\title{
Liver fluke (Fasciola hepatica) infection in cattle in Northern Ireland: a large-scale epidemiological investigation utilising surveillance data
}

Andrew W. Byrne*, Stewart McBride, Angela Lahuerta-Marin, Maria Guelbenzu, Jim McNair, Robin A. Skuce and Stanley W.J. McDowell

\begin{abstract}
Background: Liver fluke (Fasciola hepatica) is a widespread parasite of ruminants which can have significant economic impact on cattle production. Fluke infection status at the animal-level is captured during meat inspection of all animals processed for human consumption within Northern Ireland. These national datasets have not been analysed to assess their utility in uncovering patterns in fluke infection at animal- and herd-levels in Northern Ireland.

Methods: We utilised a dataset of 1.2 million animal records from $~ 18,000$ herds across 3 years (2011-2013) to assess animal- and herd-level apparent prevalence and risk-factors associated with fluke infection. Animal-level apparent prevalence was measured as the proportion of animals exhibiting evidence of fluke infection at slaughter; between herd-level infection prevalence was measured by binary categorisation of herds (infected or not). "Within herd" infection prevalence was measured using the proportion of animals within a herd that showed evidence of fluke infection per year (ranging from 0-100 \%). "Within herd" infection prevalence at the herd level was investigated using multivariable modelling.

Results: At the animal level, the proportion of animals slaughtered that exhibited evidence of infection was 21$25 \%$ amongst years. Across herds, the proportion of herds with at least one infected animal, varied between 61 and $65 \%$. However, there was a significant sampling effect at the herd-level; all herds where at least 105 animals slaughtered over the study period exhibited evidence of fluke infection (100\%). There was significant variation in terms of within-herd infection prevalence. Risk factors included herd type, long-term weather variation, geographic location (region) and the abattoir.

Conclusions: Liver fluke apparent prevalence was high at the herd-level across years. However, there was lower prevalence at the animal level, which may indicate significant variation in the exposure to fluke infection within herds. The proportion infected within-herds varied significantly in time and space, and by abattoir, herd-type and some weather variables. These data are a useful source of information on a widespread endemic disease, despite known limitations in terms of test performance (low sensitivity). As well as informing on the distribution and severity of liver fluke infection, these analyses will be used to investigate the effect of co-infection on risk for bovine tuberculosis.
\end{abstract}

Keywords: Fasciola hepatica, Meat inspection, Spatial analysis, Northern Ireland, Disease surveillance, Risk factors

\footnotetext{
* Correspondence: ecologicalepidemiology@gmail.com

Veterinary Sciences Division, Agri-food and Biosciences Institute (AFBI),

Stoney Road, Stormont, Belfast BT43SD, UK
} 


\section{Background}

Bovine fascioliasis, caused by the infection of the liver fluke Fasciola hepatica, is a worldwide problem for cattle farming, with infections having impact in terms of mortality losses, reduced weight gain, milk produced and carcass quality [1]. Within Northern Ireland, bovine fascioliasis is a widespread endemic disease of cattle. This is due to Northern Ireland having favourable habitat types and climate for Galba truncatula, the main intermediate mollusc host of $F$. hepatica. Furthermore, field based cattle farming is practiced in Northern Ireland with animals being exposed to metacercariae by grazing on pasture. While fascioliasis is considered a chronic condition of bovines, bovine mortality attributed to fascioliasis in herds in Northern Ireland has been reported (2-9 \% of deaths investigated by state laboratories 2010-2013; [2]). Surveillance data from faecal samples submitted to the Agri-food and Biosciences ekInstitute, Northern Ireland during 2012-2014 showed that between 10 and $17 \%$ of faecal samples contained eggs of F. hepatica. Furthermore, with the advent of climate change $[3,4]$ and the emergence of anthelmintic resistance $[5,6]$, it is likely that liver fluke may have an even more significant impact on agricultural production in this region [3, 4] and elsewhere [4].

A number of studies have utilised abattoir data to assess infection levels and to model the risk factors and/or spatial distribution of parasitic infections [1, 7-16]. Northern Ireland has a long history of successfully modelling parasitic infections of livestock using surveillance datasets, in particular liver fluke infection [7, 8, 17]; however, recently these data have not been analysed to garner their utility to uncover trends or their use in exploring other epidemiological hypotheses. Recent research from the Republic of Ireland used bulk milk samples from dairy farms to spatially model the distribution, clustering and relative probability of occurrence of liver fluke at a national scale [18-20]. Nevertheless, there has been a lack of similar spatial analyses of the patterns of liver fluke infection risk published across Northern Ireland recently. These data are essential, as fluke burdens carry a significant cost to farmers in terms of production and control, for example, in NI it costs $£ 50$ million per annum and ROI $€ 90$ million per annum [21]. Furthermore, co-infections of fluke and bovine tuberculosis (caused by Mycobacterium bovis) have recently been found to affect the ability to detect bTB exposed animals $[22,23]$. Co-infections with other parasites could also be impacting additively to livestock health with the potential for additional economic impacts [16].

The main goal of the present analysis was to assess the relationship between metrics of fluke infection, as measured using abattoir surveillance data, with herd level characteristics and geographically referenced environmental and meteorological predictors. The analysis demonstrates the importance of good surveillance and databasing systems and how these can be utilised for research and policy development. Despite the potential for low animal level sensitivity of abattoir surveillance, aggregating at the herd level allows for useful predictions from a readily available data source [15]. This adds value and understanding to these datasets [13]. Predictions from this work can directly inform further analyses on the potential effects of concurrent infections on the management of other diseases in cattle herds (e.g. bovine tuberculosis in Northern Ireland [24]).

\section{Methods \\ Data}

Data were gathered from the Animal and Public Health Information System (APHIS) for Northern Ireland (NI) for all cattle that were slaughtered within abattoirs throughout NI from 2011 to 2013. These data included animal-level (animal identifier, sex, age, bTB status and fluke status), herd-level (herd identifier, herd type, turnover), and geographic variables (region and farm coordinates). More details of the variables used are presented in Additional file 1: Tables S1-S6. All animals were included, with the exception of animals that did not go through an abattoir (e.g. fallen animals that were sent to knackeries; animal carcasses that were deemed not fit for human consumption). All animals processed through abattoirs in Northern Ireland would have been inspected for the presence of fluke infection as part of passive surveillance/meat inspection in compliance with UK and European legislation (EC 854/2004). This legislation requires that all livers from bovines are inspected, and livers may be inspected using visual, incision and palpation inspection for bovines $>6$ weeks old [13].

The apparent prevalence was assessed initially using descriptive statistics at animal, within-herd and acrossherd levels. The relationship between the number of animals sampled and the estimated prevalence at the herd level was also investigated.

Due to the high levels of fluke exposure across herds (see results), the apparent within-herd prevalence of infection was modelled in relation to risk factors. Prevalence was measured on a scale of 0 to 1 , by calculating the proportion of animals within a given year that exhibited evidence of fluke infection. As within-herd prevalence could be affected by the minimum number of samples from each herd, a minimum sample per herd per year of $>12$ animals was set [25]. This was based on the estimated mean within-herd sample needed for a sampling strategy using a fixed test cut-point of 1 infected animal and a within-herd prevalence of $20 \%$ [25]. There is a trade-off between increasing the minimum 
number of animals sampled per herd to increase the robustness of within-herd prevalence estimates, and the number of herds included in a dataset. In the present data set, the mean number of samples per herd was 23.6 (SD 129.2) but the median was 4, indicating a highly screwed distribution. The threshold of $>12$ animals, overall across all years, resulted in $45 \%$ of herds being included. On a yearly basis, this proportion varied between 37 and $40 \%$. Separate models were developed for each year of the study, 2011, 2012, and 2013, respectively.

Summary statistics of the independent variables are described in the Additional file 1: Tables S1-S6. These variables were selected based on availability and literature searches (e.g. $[3,15,23,26])$. Herd size (based on the number of animals tested during a full TB herd test), region (the District Veterinary Office (DVO) area; 10 administrative areas), herd type (five broad categories) were all derived from the APHIS dataset. "Herd type" was based on the recorded enterprise type within APHIS, five categories were formed, including beef breeding, beef fattening, beef rearing, dairy, and "other". The "other" category included dealers ( $n=29$ herds), exporters $(n=11)$ and unclassified or mixed herds $(n=$ 4,672). A variable called "turnover" was also included, which was calculated as the number of animals slaughtered in a given year, divided by the recorded herd-size. The majority of herds slaughtered a proportion of their herd size in a given year (i.e. turnover $<1$ ). However, some herds had a greater number of animals slaughtered than the recorded herd size (i.e. turnover $>1$ ). This arose due to high turnover in certain herds, and the fact that herd size was estimated from one static annual recording (the annual bovine tuberculosis test) at a given point during the year. Therefore, turnover captured both the buying in and slaughtering of cattle (high turnover herds have to repopulate their herds to maintain stock).

A geographic information system (GIS; ArcGIS) was used to extract data for the herds within our dataset. The coordinates for each farm (point location of herd as registered within APHIS) within the dataset were used to spatially associate the location of each cattle herd during its last ordinary herd before being sent to slaughter. With these location data, we were able to assign land use (CORINE or the UK land classification) and climatic (long-term monthly weather trends) to each farm at a $5 \mathrm{~km}$ grid scale. Official data was gathered from the UK Meteorological Office (www.metoffice.gov.uk) using the publicly available $5 \mathrm{~km}$ grid datasets (United Kingdom Climate Impact Programme (UKCIP) $5 \mathrm{~km}^{2}$ datasets). Long-term monthly data on the mean values over 19812010 for maximum and minimum monthly temperatures, the mean number of rain days $(>1 \mathrm{~mm})$ per month and humidity was used; an approach used to model $F$. hepatica previously in the UK [3] and Ireland [19]. We also gathered Vapour Pressure data, however the longterm mean monthly values available for the region only extended from 1971-2000. The mean temperature (derived from the minimum and maximum data) and climatic variance (standard deviation around the mean of each long-term monthly variable) was included. For each month, the long-term monthly mean was extracted, and then averaged these values and calculated how much variation there was in terms of the standard deviation (SD) around the mean. Land cover variables (based on CORINE and the UK land cover map 2000 [27]) were also used as a cofactor, as landscape composition has been shown to affect fluke prevalence in cattle (e.g. [26]). The CORINE categories were compressed into eight broad land types: arable, complex cultivation patterns, discontinuous urban fabric, good pasture, mixed pasture, poor pasture, mixed Agriculture/natural, and other landscape types. For a land type to be a separate category, at least $1 \%$ of herds had to be associated with the land class type. All other rarer land types were aggregated into the category called "other landscape types". An alternative land cover dataset was also explored; UK land cover categories into competing models, with the following categories included in the variable: acid grass, arable horticulture, calcareous grass, dense dwarf shrub heath, improved grassland, inland bare ground, neutral grass, open dwarf shrub heath, suburban/rural developed, and "other".

\section{Modelling}

Within herd prevalence was modelled in two ways. Firstly, severity was dichotomised into a binary outcome $(0 / 1)$, where " 0 " herds exhibited within-herd yearly prevalence in the lower $25 \%$ ile of the overall distribution; " 1 " herds exhibited within herd yearly prevalence in the upper $25 \%$ ile of the overall distribution (note, this approach does remove farms with levels of infection between the $25^{\text {th }}$ and $75^{\text {th }}$ percentile). This outcome was modelled using a multivariable logit model, with independent variables presented in Additional file 1: Tables S1-S6. The fit of the model to the data was assessed using a Hosmer-Lemeshow goodness-of-fit test (calibration); $P \leq 0.05$ indicated significant lack of fit to the data. The discriminatory ability of the model was assessed using the Area Under the Curve (AUC) from a Receiver Operated Curve (ROC). The AUC is measured on a continuous scale from 0 to 1 ; an AUC of 0.5 is no better than random, $>0.7$ is considered an adequate model, > 0.8 is a good model, and $>0.9$ is considered an excellent model. The sensitivity (probability that a positively classified farm is truly positive), specificity (probability that a negatively classified farm is truly negative), and the percentage of farms that were correctly classified, using 
a standard cut-point of 0.5 was reported too. Assessment of whether there was any spatial autocorrelation in the residuals of the final models was assessed by plotting a semi-variogram using the package geo $\mathrm{R}$ [28] within the $R$ statistical environment [29]. A $95 \%$ confidence envelope was created by randomly permuting the data across the locations 99 times (i.e. assuming no spatial autocorrelation) following [23] and then plotting the envelope within which $95 \%$ of the semivariances lay [28]. The observed and predicted outcomes from the models were mapped using ArcGIS ${ }^{\circ}$ (version 9.2; Redlands, CA: Environmental Systems Research Institute), with spatial variation presented using Inverse Weighted Distance (IWD) interpolation (Fig. 2).

The second modelling approach was to model the within-herd prevalence as a continuous outcome (proportion/fraction) using Fractional Response Regressions [30] and Generalised Linear Modelling. The benefit of this modelling approach is that all the data can be used (as opposed to the binary approach used above), and the expected outcome (fraction positive per year) can be modelled as a continuous variable while bounding the outcome between $\mathrm{O}$ and 1 (i.e. between 0 and $100 \%$ positive), in comparison with an ordinary least squares (OLS) model [31]. The models were developed using Generalised Linear Model (GLM) modelling with the proportion infected as the outcome using a logit link function and robust standard errors and compared the results with those of the fractional response regression. We compared the predictions from these models against the observed proportion infected, but binning the predicted proportions in categories (groups of 0.05 , respectively) and visually assessing the relationship (calibration graph; [32, 33]).

During model building, all independent variables were tested for association with the outcome variable using univariable models (either logistic regressions or GLMs). The functional form of the relationship between the outcome variable and continuous predictors was assessed using LOWESS smoothed curves. Where necessary, independent variables were suitably transformed [34]. Predictors were retained for the multivariable model if associated with the outcome at $P<0.2$. Throughout, model building was undertaken using backwards, forwards and stepwise sequential model building [34]. Correlations between independent variables were assessed, and Variance Inflation Factor (VIF) was used during model building to assess if multi-collinearity may have been a problem (using OLS models). The final models were compared to assess their composition, and Akaike's information criteria (AIC) were used if there were competing final models. The best models were those with the lowest AIC value. All statistical analyses were undertaken in Stata 14 (StataCorp 2015, College Station, TX).

\section{Results}

Descriptive analysis

Overall, there were 1,216,579 animal level records within the dataset (Table 1). Of these, 288,114 (23.68\%; $95 \% \mathrm{CI}$ : 23.61-23.76 \%) animals were recorded with signs of fluke infection. The percentage of animals with fluke varied across years, with higher apparent prevalence in 2011 (24.80 \%) and 2013 (24.85\%), than 2012 (21.37\%). This difference between 2012 and other years was statistically significant (2012 vs 2011: OR: 0.82; $P<0.001 ; 2012$ vs 2013: OR: $0.82 ; P<0.001 ; n=1,216,579)$, while there was no difference between 2011 and $2013(P=0.619 ; n=1,216,579)$.

The mean within-herd percentage positive overall was $23.18 \%$ (median $14.86 \%$; IQR: 0-35.53; Table 2). The within-herd percentage varied across years; varying from 24.60 to 21.38 \% from 2011-2013 (Table 2).

The herd-level fluke infection status was assessed for each herd-year and for each herd respectively. In total, there were 39,997 herd-years within the dataset, of which 25,259 herd-years (63.15\%) were positive for fluke (where at least one animal with fluke found within the herd-year). This varied over time, between 64.84 and $60.85 \%$ during 2011-2013 (Table 3). Aggregating across years, there were 18,266 herds represented in the dataset, with 12,621 herds having evidence of fluke infection within their herd over the study period $(69.10 \%$; $95 \% \mathrm{CI}$ : 68.42-69.77\%). However, there was a significant sampling effect found, with a relationship between the number of animals sampled, and the probability of being an exposed herd (see next section).

\section{Relationship between numbers of animals sampled and herd status}

There was a significant relationship between the numbers of animals sampled (culled within an abattoir) per herd across years 2011-2013, and the probability of that herd having a positive exposed status (log(no. samples) OR: 3.68; $P<0.001$; Table 4). Herd-level percentage positive increased from $34.22 \%$ for herds which had between one and four animals culled between 2011 and 2013, up to $100 \%$ positive for herds with 105 or more animals submitted to abattoir over the study period (Table 4). The relationship between apparent prevalence

Table 1 Animal level variation in post-mortem fluke infection status across years (2011-2013) in Northern Ireland

\begin{tabular}{lllll}
\hline Animal fluke status & 2011 & 2012 & 2013 & Total \\
\hline No & 311,891 & 316,109 & 300,465 & 928,465 \\
(\%) & 75.20 & 78.63 & 75.15 & 76.32 \\
Yes & 102,862 & 85,905 & 99,347 & 288,114 \\
(\%) & 24.80 & 21.37 & 24.85 & 23.68 \\
Total & 414,753 & 402,014 & 399,812 & $1,216,579$ \\
\hline
\end{tabular}


Table 2 The mean percentage of animals within-herds that exhibited evidence of liver fluke infection

\begin{tabular}{lllll}
\hline & 2011 & 2012 & 2013 & Mean \\
\hline Mean within-herd \% & $24.60 \%$ & $21.38 \%$ & $23.55 \%$ & $23.18 \%$ \\
Std. Dev. & 0.281 & 0.270 & 0.274 & 0.276 \\
Total herds & 13,907 & 13,655 & 12,435 & 13,332 \\
\hline
\end{tabular}

and sampling was steep (Fig. 1), with $95 \%$ of herds with 20-39 animals sampled being positive for fluke infection. This indicates that effectively all herds (with a large numbers of animals slaughtered to aid detectability) in Northern Ireland were exposed to fluke (this could be either home bred or bought in animals) over a temporal resolution of three years.

Similar patterns were found when status was assessed on individual years. There was a significant relationship between the number of samples per herd per year and the \% herds considered exposed in 2011 (log (no. samples) OR: 3.54; $P<0.001$ ), 2012 (OR: 3.32; $P<0.001$ ), and 2013 (OR: 3.35; $P<0.001$ ). All herds which culled $>$ 160 animals in 2011, > 227 in 2012 and > 302 in 2013 respectively, were fluke positive (Table 5 ).

\section{Multivariable logit model results}

The binary logit outcome model categorised high and low prevalence (referred to as "severity") herds, respectively based on the being within the top quartile of all herds or being in the bottom quartile of all herds $(0 / 1)$. The cut-point for high-risk herds was average withinherd prevalence of $>33.33 \%$ (coded as " 1 "); the cutpoint for the lower risk herds was $<11.03 \%$ (coded as “0”). This resulted in 7,746 total herds, 3,997 (51.60\%) high risk herds and 3,749 (48.40\%) low risk herds across the 3 years of this study.

\section{1 model}

The final 2011 logit model contained herd severity estimates for 2,472 herds, and exhibited a pseudo- $\mathrm{R}^{2}$ (McFadden's) of 0.28. The discriminatory ability of the model was good (AUC: 0.82). Apparent sensitivity was

Table 3 Herd level variation in fluke infection status, with herds categorised as exposed (with at least one infected animal culled in a given year) or non-exposed (without any culled animals with evidence of fluke infection at post-mortem) across years (2011-2013) in Northern Ireland

\begin{tabular}{lllll}
\hline Herd fluke status & 2011 & 2012 & 2013 & Total \\
\hline Non-Exposed & 4,890 & 5,346 & 4,502 & 14,738 \\
$(\%)$ & 35.16 & 39.15 & 36.20 & 36.85 \\
Exposed & 9,017 & 8,309 & 7,933 & 25,259 \\
$(\%)$ & 64.84 & 60.85 & 63.80 & 63.15 \\
Total & 13,907 & 13,655 & 12,435 & 39,997 \\
\hline
\end{tabular}

Table 4 The overall status of herds in NI relative to the number of samples taken per herd over the period 2011-2013. Note, the cut-point where there were no fluke free herds was 105 animals sampled

\begin{tabular}{llllllllll}
\hline $\begin{array}{l}\text { Herd } \\
\text { status }\end{array}$ & \multicolumn{7}{c}{ Samples } \\
& $1-4$ & $5-9$ & $10-19$ & $20-39$ & $40-79$ & $80-159$ & $>160$ & Total \\
\hline 0 & 4,535 & 709 & 272 & 93 & 31 & 5 & 0 & 5,645 \\
$\%$ & 65.78 & 30.36 & 12.97 & 4.70 & 1.62 & 0.32 & 0 & 30.91 \\
1 & 2,359 & 1,626 & 1,825 & 1,887 & 1,878 & 1,560 & 1,485 & 12,620 \\
$\%$ & 34.22 & 69.64 & 87.03 & 95.3 & 98.38 & 99.68 & 100 & 69.09 \\
Total & 6,894 & 2,335 & 2,097 & 1,980 & 1,909 & 1,565 & 1,485 & 18,265 \\
\hline
\end{tabular}

$84.78 \%$, specificity was $67.82 \%$, and $77.47 \%$ of herds were correctly classified according to the predictions of the model. The model fitted the data well (HosmerLemeshow test: $P>0.05)$. There was no evidence of spatial autocorrelation within the residuals from the final model.

The final model suggested that there was significant variation in risk across abattoirs, herd types and DVO regions (Table 6). There was a large difference in the risk amongst abattoirs; for example, the odds ratio for abattoir 1 relative to abattoir 0 was 10.79 $(P<0.001)$. This equated to $35 \%$ of herds associated with abattoir 0 being in the high risk group, whereas $83 \%$ of herds associated with abattoir 1 were in the high risk group. Dairy herds had the highest risk of being in the high severity category across herd types (OR: 1.65 relative to beef breeding; $P<0.001$ ); $66 \%$ of dairy herds were in the high risk category in comparison to a mean of $51 \%$ across other herd types. Beef fattening herds had significantly lower risk of being classified as a high severity herd relative to beef breeding (OR: $0.71 ; P<0.05$ ). Fluke risk was negatively associated with increasing long-term minimum temperature $(P<0.001)$. Herds within the regions of Derry, Armagh, Larne (County Antrim) and Omagh (County Tyrone) had the lowest odds of being high severity herds; whereas herds in Ballymena (County Antrim) and Enniskillen (County Fermanagh) had the highest probability of being high severity herds.

The distribution and status of farms making up this dataset is presented in Fig. 2a. Predictions from the logit model are presented in Fig. 2d. The distribution of these herds is widespread across Northern Ireland, with some notable exceptions in North Tyrone/South Derry, NorthEast Antrim, South-East Down, and the greater Belfast area (see Additional file 1: Figures S3 and S4). These areas correspond to marginal or unproductive lands (upland, and areas with bog) and urban areas (Fig. 2a). 


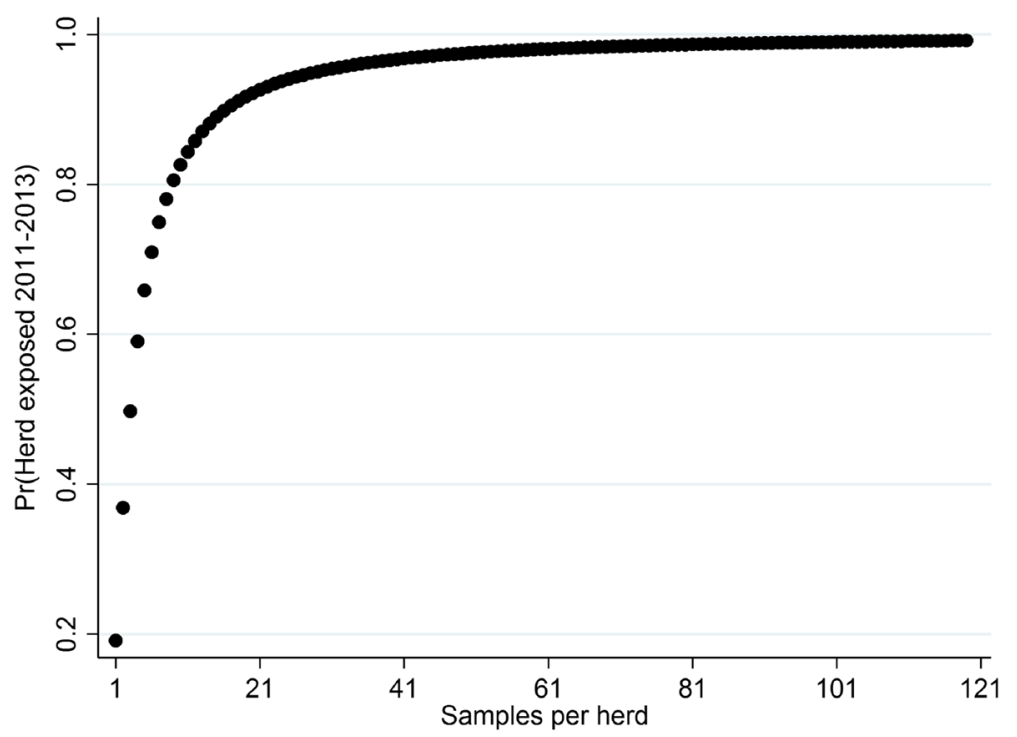

Fig. 1 The relationship between the probability of a herd having evidence of fluke infection and the number of animals slaughtered per herd in Northern Ireland 2011-2013

\section{2 model}

The final multivariable logit model contained 2,408 herds, with a pseudo- $\mathrm{R}^{2}$ of 0.32 . The discriminatory ability of the model was very good (AUC: 0.86 ) and exhibited apparent sensitivity of $76.64 \%$, specificity of $79.55 \%$, and correct classification of $78.32 \%$. The model fitted the data well (Hosmer-Lemeshow test: $P>0.05$ ), and there was no evidence of spatial autocorrelation in the residuals from the final model.

A risk map derived from the model's predictions in presented is Fig. 2e, and compared to observed point maps derived from observed data (Fig. 2b). Fluke severity risk varied significantly amongst the predominant abattoir used, herd-type and region (Table 6). Herds predominately using abattoirs 1 (OR: 9.23) and 7 (OR: 6.93) were of considerably higher risk of being a high risk herd relative to herds using abattoir $0(P<0.001)$. In 2012, $24 \%$ of herds using abattoir 0 were in the higher prevalence category, whereas 69 and $77 \%$ of herds using abattoir 1 and 7 were high risk respectively. Dairy herds again were the highest risk amongst herd types (OR: 2.19 relative to beef breeding; $P<0.001$ ); $58 \%$ of dairy herds were in the high prevalence category, whereas the average proportion across the other categories was $33 \%$. Fluke severity risk was also positively associated with increasing long-term mean maximum-temperature $(P=$ $0.011)$ and with increasing number of rain days $(P<$ $0.001)$.

\section{3 model}

The final 2013 multivariable logit model contained 2,500 herds and had a pseudo- $R^{2}$ of 0.33 . The model exhibited very good discriminatory ability with an AUC of 0.86 . Using a probability cut-off of 0.5 , the model exhibited sensitivity of $82.97 \%$, specificity of $77.12 \%$ and was able to correctly classify $80.40 \%$ of herds. Residuals from the final model did not exhibit spatial autocorrelation (Additional file 1: Figures S1 and S2). A risk map derived from the model's predictions in presented in Fig. $2 f$.

Variation in the probability of a herd having a high fluke infection severity score varied significantly by the predominant abattoir, herd type, region, long-term variation in rain fall (SD), mean humidity and minimumtemperature (Table 6). Dairy herds had the highest risk of exhibiting high severity fluke infection relative to beef or other herd types. Armagh (south-east region) had the lowest risk, while Ballymena (north-east region) had the highest risk of being in the severe fluke category. The risk of severe fluke infection decreased with the increasing variation in rainfall, minimum temperature and humidity.

\section{Proportion infected model}

Both the GLM and the fractional response regression models produced very similar results. Consequently, the GLM models are presented here only. The outcomes from the models for 2011, 2012 and 2013, respectively, are presented in Table 7 . The ability of the model to capture the relative within-herd prevalence was assessed by plotting the predicted prevalence against the observed prevalence. The calibration of the models was generally good, with some evidence of the models marginally overestimating within-herd prevalence at low infection levels, 
Table 5 The yearly status of herds in NI relative to the number of samples taken per herd for the years 2011-2013, respectively. Note, the cut-point where there were no fluke free herds was 160 animals sampled in 2011, 227 in 2012, and 302 in 2013

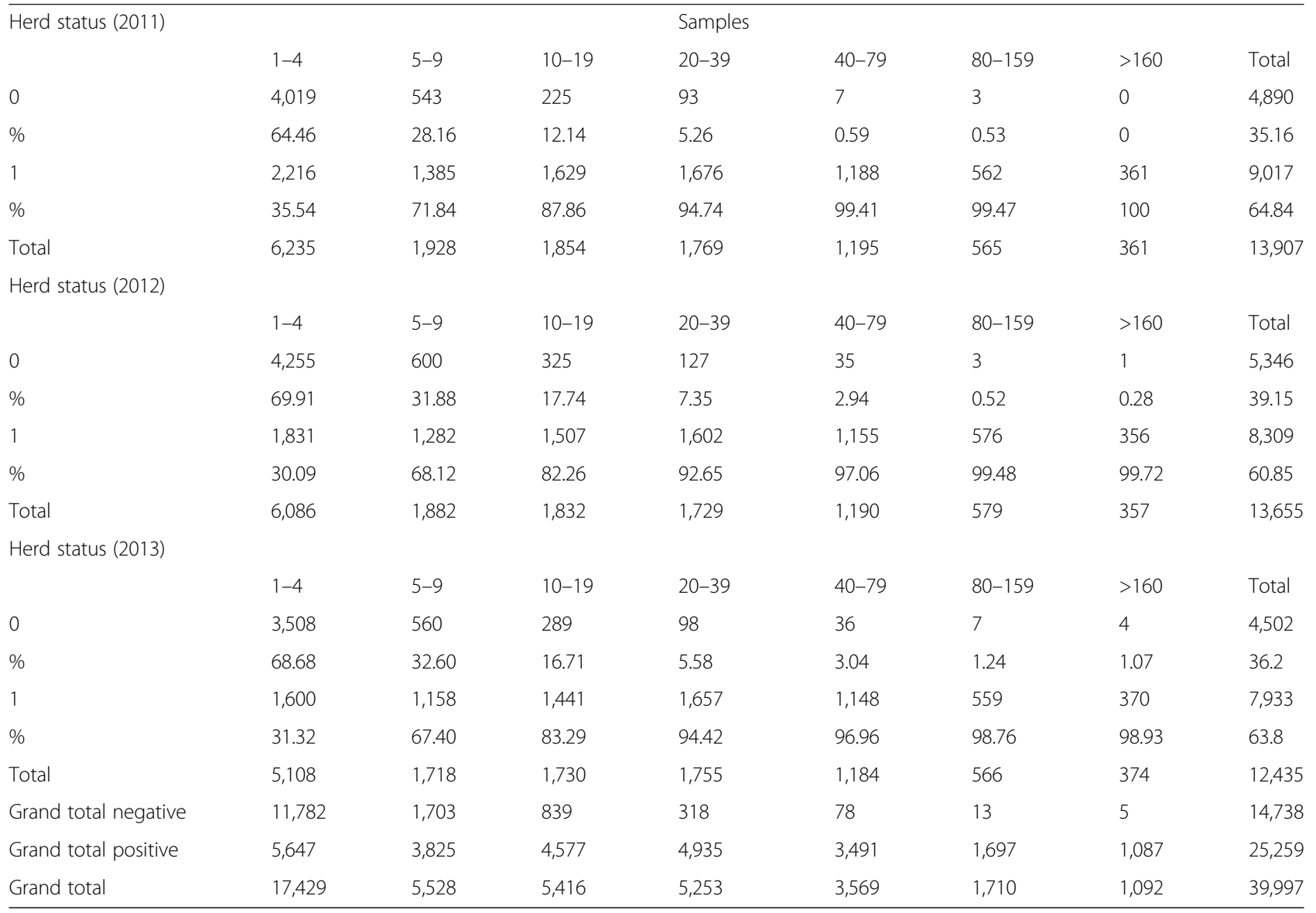

and underestimating the mean within-herd prevalence at the high infection levels (see Additional file 1: Figures S11-S13).

Across models, abattoir, region and herd type were significant predictors of within-herd apparent prevalence. Abattoir 1 was consistently associated with the highest proportion of animals with evidence of fluke infection across years (OR: $1.95-2.16$ relative to abattoir $0 ; P<$ 0.001). Abattoir 4 was consistently associated with the lowest proportion of animals with evidence of fluke infection across years (OR: $0.59-0.64$ relative to abattoir 0; $P<0.001)$. Dairy herds exhibited a higher proportion of animals with evidence of fluke infection relative to other herd types (OR: 1.06-1.19 relative to beef breeding herds; $P<0.01$ : 2011-2012; $P<0.1$ : 2013). Ballymena, Coleraine and Enniskillen had significantly higher within-herd prevalence $(P<0.05$; Table 7$)$ relative to Armagh which had the lowest within-herd prevalence. Herd size was negatively associated with increasing within-herd prevalence only during 2013 (OR: 0.97 per 100 animals; $P<0.001)$.

Across years, different climatic variables were associated with within-herd prevalence. In 2011 and 2012, within-herd prevalence was positively associated with increasing long-term variation in humidity (OR: 1.07-1.09; $P<0.01)$. In 2012, fluke within-herd prevalence was also associated with decreasing humidity (OR: 0.93; $P<0.05$ ) and lower variation in minimum temperatures (OR: 0.78; $P<0.05)$. In 2013, there was an association with the long-term minimum temperature and within-herd fluke prevalence (OR: 0.89; $P<0.001$ ).

\section{Discussion}

Our study has demonstrated that there are high levels of liver fluke exposure at animal and herd levels in Northern Ireland. Overall, between 21 and $25 \%$ of all animals were recorded with evidence of fluke infection across the years of the study. A similar level of fluke infection from an abattoir from northern Portugal/Spain was reported, where $28 \%$ of 776 animals slaughtered were infected with liver fluke [35]. However, the levels of fluke infection reported at abattoir are lower than previous post-mortem studies undertaken in the Republic of Ireland [12] and Northern Ireland [36]. Murphy et al. [12] reported that $65 \%$ of livers from culled cows that were laboratory inspected had fluke or pathology 
Table 6 Outcomes from three multivariable logit models relating the risk of cattle herd exhibiting high severity fluke infection for the years 2011, 2012 and 2013, respectively

\begin{tabular}{|c|c|c|c|c|c|c|c|}
\hline Logit & & 2011 & $N=2,472$ & 2012 & $N=2,408$ & 2013 & $N=2,500$ \\
\hline Predictor & & OR & Sig. & OR & Sig. & OR & Sig. \\
\hline \multirow[t]{8}{*}{ Abattoir } & 0 & 1 & & 1 & & 1 & \\
\hline & 1 & 10.790 & $* * *$ & 9.231 & $* * *$ & 16.595 & $* * *$ \\
\hline & 2 & 5.021 & $* * *$ & 4.735 & $* * *$ & 2.720 & $* * *$ \\
\hline & 3 & 8.209 & $* * *$ & 4.551 & $* * *$ & 11.665 & $* * *$ \\
\hline & 4 & 0.221 & $* * *$ & 0.093 & $* * *$ & 0.195 & $* * *$ \\
\hline & 5 & 0.483 & $* *$ & 0.419 & ** & 0.397 & $* * *$ \\
\hline & 6 & 1.438 & & 0.894 & & 1.054 & \\
\hline & 7 & 3.725 & $* * *$ & 6.927 & $* * *$ & 15.264 & $* * *$ \\
\hline Rain days & mean_rain & & & 1.536 & $* * *$ & & \\
\hline SD Rain days & sd_rain & & & & & 0.513 & * \\
\hline Max. temp. & maxtemp & & & 1.573 & * & & \\
\hline Min. temp. & mintemp & 0.630 & $* * *$ & & & 0.574 & $* * *$ \\
\hline Humidity & humidity & & & & & 0.701 & * \\
\hline \multirow[t]{5}{*}{ Herd type } & Beef breeding & 1 & & 1 & & 1 & \\
\hline & Beef fattening & 0.713 & * & 0.950 & & 0.736 & \\
\hline & Beef rearing & 0.943 & & 0.684 & & 0.814 & \\
\hline & Dairy & 1.651 & $* * *$ & 2.185 & $* * *$ & 1.062 & \\
\hline & Other & 1.102 & & 1.197 & & 0.544 & $* * *$ \\
\hline \multirow[t]{10}{*}{ Region } & Armagh & 1 & & 1 & & 1 & \\
\hline & Ballymena & 1.810 & * & 6.192 & $* * *$ & 5.069 & $* * *$ \\
\hline & Coleraine & 1.191 & & 2.367 & $* * *$ & 3.333 & $* * *$ \\
\hline & Derry & 0.832 & & 1.158 & & 1.423 & \\
\hline & Dungannon & 1.274 & & 2.066 & $* *$ & 1.021 & \\
\hline & Enniskillen & 1.602 & & 1.566 & & 1.850 & \\
\hline & Larne & 0.910 & & 3.390 & $* * *$ & 3.948 & $* * *$ \\
\hline & Newry & 1.043 & & 1.526 & & 1.194 & \\
\hline & Newtownards & 1.142 & & 1.629 & * & 2.136 & $* * *$ \\
\hline & Omagh & 0.699 & & 1.136 & & 1.830 & \\
\hline
\end{tabular}

Significance (Sig.): ${ }^{*} P<0.05 ;{ }^{*} P<0.01 ; * * * 0.001$

attributable to fluke infection. In Northern Ireland, an abattoir survey in 1964-1965 found that $88 \%$ of cattle had been infected with $F$. hepatica at some stage of their life [36]. This reflects the fact that routine surveillance can have low sensitivity to detect infection. A study by Rapsch et al. [37] suggested that meat inspection for liver fluke may exhibit a sensitivity of $63.2 \%$ (55.6-70.6 $\%)$, meaning that the true levels of infection may be between 1.5 and 2 times the apparent prevalence. In Switzerland, abattoir surveys suggested that the prevalence of fluke infection in cattle was between 8.4 and 15\% [38-40]. However, accounting for test sensitivity, the true prevalence in a study of 1,331 animals was $18.0 \%$ (95 \% credible intervals 15.9-20.3\%), which indicated that approximately a third of infected livers were missed by meat inspection during that study [37]. It should be noted, however, estimates of the sensitivity of routine meat inspection in Northern Ireland is currently unknown.

Importantly, the levels of infection reported here are considerably higher than reports from meat inspection data from Denmark presented in Olsen et al. [15], where only $3-4 \%$ of animals were deemed infected per annum. Similarly, in Sweden meat inspection data suggested that animal level prevalence was $3 \%$ in 2005, but rose to $9.8 \%$ in 2012 and $11 \%$ in 2013 (reported in $[41,42]$ ). These international differences are possibly the result of a true difference in the exposure to liver fluke between the countries $[4,42]$. The island of Ireland is possibly the best 

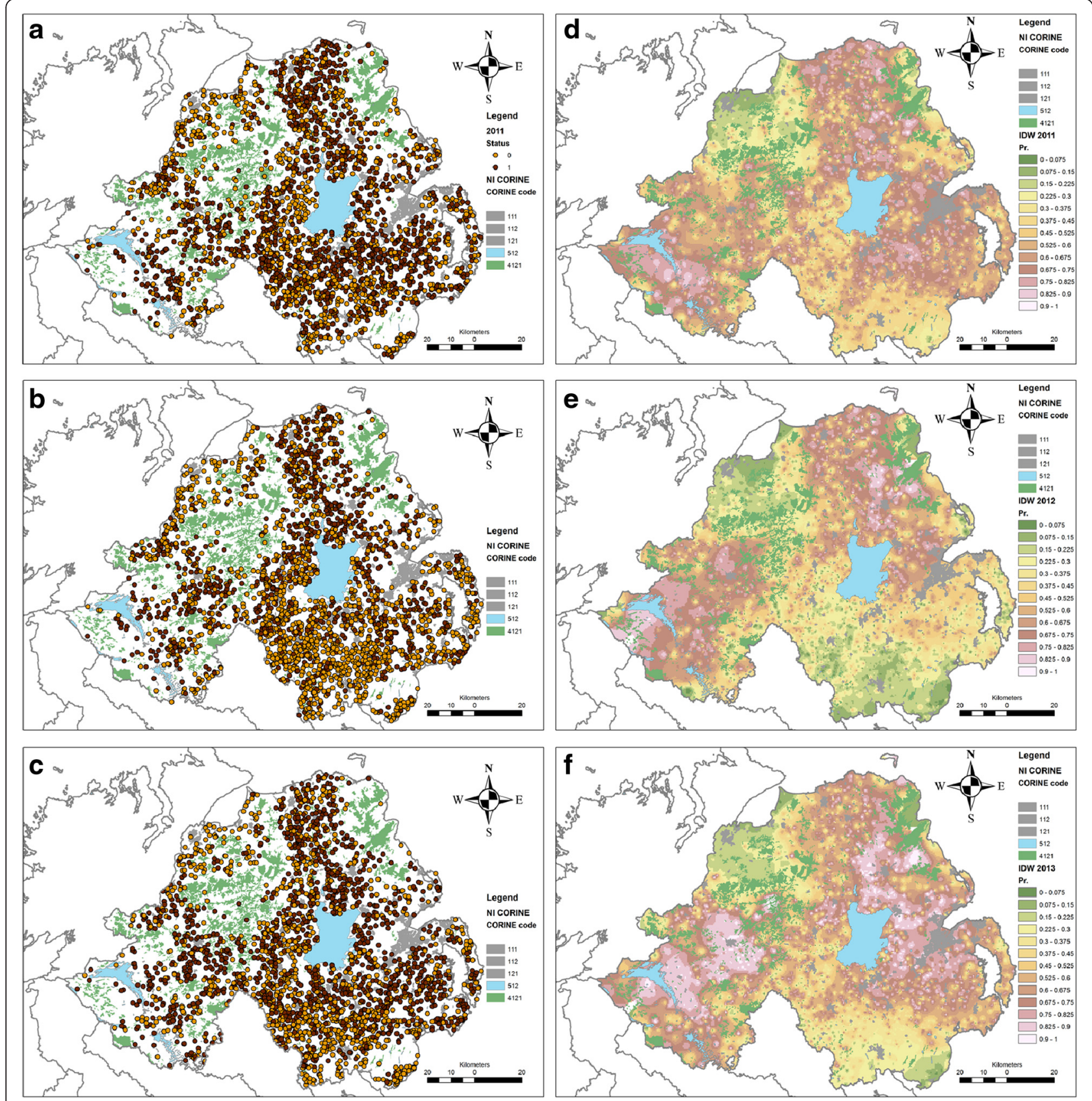

Fig. 2 Observed and predicted within-herd liver fluke prevalence in Northern Ireland based on meat inspection data. Panels a-c depicts the distribution of herds with high or low within-herd infection prevalence for 2011-2013, respectively. Panels d-f represents predicted probability of a herd being in a high infection category from 2011-2013 from a logistic model, respectively. The CORINE land cover types presented in this map corresponds with: $111=$ Continuous urban fabric; $112=$ Discontinuous urban fabric; $121=$ Industrial and commercial units; $512=$ Water bodies; $4121=$ Unexploited bogs

suited region within Europe for liver fluke to thrive, both in terms of climate and habitat suitability, as highlighted by recent international modelling efforts $[4,43,44]$. Furthermore, climate projections suggest the weather on the island of Ireland will be more favourable for fluke in the future [3, 4]. Warmer, wetter winters will ensure survival of fluke metacercariae and their intermediate host within the Irish landscape, increasing risk of transmission. Furthermore, the advent of flukicidal resistance is an emerging issue having a negative impact on the control of fluke infection $[5,6]$.

At herd level, 61-65\% of all herds had some evidence of fluke infection in the current study. 
Table 7 Generalised linear models (GLM) relating the proportion of animals with evidence of fluke infection at post-mortem withinherds for the years 2011, 2012 and 2013 respectively. The GLM was fitted with a logit link function to ensure predictions from the model would be constrained between 0 and 1 (i.e. 0 to $100 \%$ infected within herd)

\begin{tabular}{|c|c|c|c|c|c|c|c|}
\hline GLM & & 2011 & $N=4,680$ & 2012 & $N=4,794$ & 2013 & $N=4,874$ \\
\hline Predictor & & OR & Sig. & OR & Sig. & OR & Sig. \\
\hline \multirow[t]{8}{*}{ Abattoir } & 0 & 1 & & 1 & & 1 & \\
\hline & 1 & 1.953 & $* * *$ & 2.158 & $* * *$ & 2.014 & $* * *$ \\
\hline & 2 & 1.652 & $* * *$ & 1.798 & $* * *$ & 1.307 & $* * *$ \\
\hline & 3 & 1.817 & $* * *$ & 1.777 & $* * *$ & 1.911 & $* * *$ \\
\hline & 4 & 0.613 & $* * *$ & 0.636 & $* * *$ & 0.586 & $* * *$ \\
\hline & 5 & 0.791 & $* *$ & 0.979 & & 0.758 & $* *$ \\
\hline & 6 & 1.110 & & 1.086 & & 0.926 & \\
\hline & 7 & 1.442 & $* * *$ & 2.005 & $* * *$ & 1.936 & $* * *$ \\
\hline Herd size & herdsize & & & & & $0.971 \wedge$ & $* * *$ \\
\hline Min. temp. & mintemp & & & & & 0.885 & $* * *$ \\
\hline SD min. temp. & SD mintemp & & & 0.777 & * & & \\
\hline SD humidity & SD humidity & 1.074 & $* *$ & 1.088 & $* *$ & & \\
\hline Humidity & humidity & & & 0.931 & * & & \\
\hline \multirow[t]{5}{*}{ Herd type } & Beef breeding & 1 & & 1 & & 1 & \\
\hline & Beef fattening & 0.919 & * & 0.938 & & 0.917 & $*$ \\
\hline & Beef rearing & 0.978 & & 0.921 & & 0.960 & \\
\hline & Dairy & 1.098 & $* *$ & 1.188 & $* * *$ & 1.059 & \\
\hline & Other & 1.011 & & 1.028 & & 0.940 & \\
\hline \multirow[t]{10}{*}{ Region } & Armagh & 1 & & 1 & & 1 & \\
\hline & Ballymena & 1.229 & $* * *$ & 1.585 & $* * *$ & 1.374 & $* * *$ \\
\hline & Coleraine & 1.139 & $* *$ & 1.379 & $* * *$ & 1.359 & $* * *$ \\
\hline & Derry & 1.025 & & 1.273 & * & 1.148 & \\
\hline & Dungannon & 1.093 & & 1.195 & $* * *$ & 1.032 & \\
\hline & Enniskillen & 1.318 & $* * *$ & 1.438 & $* * *$ & 1.156 & $*$ \\
\hline & Larne & 1.001 & & 1.390 & $* * *$ & 1.373 & $* * *$ \\
\hline & Newry & 1.034 & & 1.086 & & 0.982 & \\
\hline & Newtownards & 1.074 & & 1.120 & * & 1.296 & $* * *$ \\
\hline & Omagh & 1.041 & & 1.317 & $* * *$ & 1.064 & \\
\hline
\end{tabular}

$\Lambda=$ per 100 animals; Significance (Sig.): ${ }^{*} P<0.05 ;{ }^{* *} P<0.01 ; * * P<0.001$

However, we have shown that there was a strong sampling effect with this estimate (Fig. 1). Betweenherd prevalence for herds where only 1-4 animals were culled was between 30 and $36 \%$. The apparent prevalence increased quickly with sample numbers, with apparent prevalence increasing to $82-88 \%$ when 10-19 animals were sampled per herd per annum. For large herds with many animals' culled (> 105), the herd-level prevalence reached $100 \%$ across the years of the study. These results concur broadly with recent prevalence studies in Ireland that suggest that $82 \%(n=3,764)$ of the dairy herds sampled exhibited evidence of exposure to fluke infection (assessed by testing bulk milk samples; [18]). These studies indicate that the vast majority of herds in Ireland have been exposed to liver fluke infection (which could be as a result of exposure on farm, or buying in infected animals) in contrast to other European countries [4, 41, 43]. For example, using similar data (meat inspection) to the present study herd-level between farm prevalence in Denmark has been reported as between 25 and $29 \%$ [15]. In the Netherlands, in a study of 2,500 farms, $30.2 \%$ exhibited evidence of liver fluke exposure (seropositive animals present; [4, 45]). Reports from Belgium found $37 \%$ of herds seropositive [46], in Portugal 11-42 \% [47] and in Germany $24 \%$ positive [48]. The seroprevalence of fluke in cattle herds in Sweden has been reported as 
being 21-29 \% [41, 42]. Interestingly, during that Swedish study $17 \%$ of herds that were sero-positive did not have evidence of infection in animals at slaughter, highlighting the poor sensitivity of meat inspection $[41,42]$.

\section{Temporal and spatial trend}

Over the study period, there was no clear increasing or decreasing trend in apparent prevalence of liver fluke infection. Instead, metrics of infection at animal, withinherd, and between herd levels, suggested that 2012 had significantly lower infection levels than either 2011 or 2013. A contemporary study of fluke infection levels in sheep in Ireland suggested also that there was not significant inter-annual variation in fluke prevalence over a similar period [44].

There was significant variation in risk depending on the region (DVO area) in which the farm resided. Across models, there was greater likelihood of herds being higher risk if they were found in Ballymena or Coleraine, relative to other DVOs. After model building, we did not find evidence of spatial autocorrelation amongst model residuals, in comparison with randomised variograms. This suggests that most of the residual spatial information was captured by the fixed effects in the model. There were a number of fixed effects that were spatially explicit, that may have helped to control for spatial variation, including the REGION fixed effects.

\section{Dairy herd's higher risk}

Across models, we consistently found that there was higher risk of fluke infection in dairy herds than in nondairy herd types. Dupuy et al. [13] used cluster analysis to group variables from meat inspection data, to assess its utility in syndromic surveillance in France. The authors found that liver fluke infection was associated with beef cattle. However, liver fluke infection also clustered with female cows and older cows, both of which are characteristic of dairy cattle herds. Murphy et al. [12] reported high levels of polyparasitism in Irish beef and dairy cattle; however, they did not present evidence of a clear herd-type bias. In Denmark, Olsen et al. [15] found that $35 \%$ of non-dairy herds had evidence of fluke infection, compared to $58 \%$ of dairy herds. However, their final model reported that medium sized dairy $(30-100$ animals) herds had a lower risk of being infected (53\%) with liver fluke than non-dairy herds (56\%) using meat inspection data. In the present study, no interactions between herd-size and type-was found across models $(P>$ 0.1 across models). The actual mechanism as to why dairy herds tended to have higher within-herd prevalence is yet to be determined, but could be related to the frequency, timing and type of anthelmintics used, the age profile of the herds, differences in habitats or the grazing management amongst herd types.

\section{Inter-abattoir variation}

One of the most significant factors affecting the variation in fluke prevalence in the present study was the main abattoir used by the farmer over the study period. The average proportion of animals disclosed as fluke positive could be twice as high in one abattoir relative to another abattoir in a given year. Similar variation between slaughterhouses has been reported from Denmark [15]. There, herds associated with the highest disclosing abattoir were 3.4 times more likely to be infected (62\%) than the lowest disclosing abattoir (18\%; [15]). In the present study, across all models, abattoir 1 was associated with herds with high prevalence, while abattoir 4 had the lowest proportion positive. However, the relative rank of other abattoirs varied somewhat across years and model types. The variation in abattoir is related to the performance of meat inspection and the region in which the abattoir was based. While generally animals would be processed in abattoirs close to the herd, there was variation in this pattern across Northern Ireland. When looking at the relationship between abattoir and region, there were some weak correlations found, however Variance Inflation Factor (used in OLS models) was low. A correlation matrix between region and abattoir across the study period suggested that there were some farmers from each DVO sending animals to each of the respective abattoirs. This is maybe linked to the variation in prices achieved across the market.

Previous research from Ireland has found significant variation in the disclosure by meat inspection of bovine tuberculosis (lesions) from slaughter houses [49, 50]. Frankena et al. [49] found that there was a large difference in the rates of bTB like lesions across 42 different factories ranging from 0 to 58 per 10,000 animals slaughtered during 2003-2004. A follow-up survey from 2005-2007 suggested that the variation across factories reduced between surveys (a seven-fold difference to a five-fold difference in disclosure) and the mean proportion disclosed increased [50], indicating that there was scope for improvements in standardisation and the ability to increase detection probabilities [51]. Collins [52] suggested that variation in the performance between abattoirs may be related to a number of factors including line speed, light intensity, inspector's experience and motivation [52]. Other issues may relate to variation in the actual recording (data quality) of fluke infection between abattoirs. The large variation between abattoirs cannot easily be explained currently, and may be an important future research topic in Northern Ireland. 
Long-term weather correlated with fluke infection but not robust patterns

We found that long-term climate variables were correlated with within-herd prevalence; however, there was large variation in the weather variables selected after modelling building across years and models (Tables 6 and 7). Across three of the models, there was a significant negative association between increasing minimum temperature and liver fluke prevalence. This would indicate that areas that were cooler than average may have increased risk of having higher within-herd prevalence, which is in keeping with larger scale studies [43]. However, in one model, there was a positive association between mean maximum temperature and within-herd fluke prevalence. Such variation in association between weather variables and metrics of fluke prevalence has been reported previously in a study in England and Wales [26]. Surprisingly, variation in rainfall was retained as a predictor in only two models in the current study. In those models, there was an increased risk of higher prevalence with increasing rainfall days, and a decreased risk with the long-term variation in rainfall days, respectively. A recent study comparing fluke infection in sheep between Ireland, Switzerland and Italy found that longer-term weather variables (temperature and rainfall) explained between country variations in fluke prevalence, but were not associated with year-to-year variation within country [44]. Instead, shorter-term weather variation in mean temperature, rainfall and seasonality was important in explaining the variation from year to year within country [44]. McCann et al. [26] found that both mean 5-year and contemporaneous weather variables were associated with fluke exposure in herds in England and Wales. However, there was only a marginal benefit to using a 5 -year mean with contemporaneous weather, than using a single time point alone.

At the univariable level, we found some evidence of variation in fluke prevalence depending on the landscape/land cover categories derived from either CORINE or the Land Classification Map. However, neither broad landscape/land cover categories were retained in any of our final models. This concurs with work undertaken Ducheyne et al. [43], who modelled fluke spatial distribution across Europe using weather and vegetation indices. The authors reported that weather variables were very important predictors in their models; however the vegetation variables were not important. McCann et al. [26] found weather variables were consistently important predictors of fluke prevalence in England and Wales, but also found that landscape features were also important for some models. For example, they found the improved grassland was a positive predictor of fluke infection in four of their models. In Switzerland, soil conditions and forest cover was also used to create indicative map of fluke risk, based on the potential exposure of herds to the intermediate host Galba truncatula [37]. Other authors have highlighted how the lack of detail of land cover maps may reduce the accuracy of generating risk maps for liver fluke [53]; indeed high resolution mapping may help to elucidate the risk to individual farms and their landscape composition.

\section{Limitations}

The farm locations were only measured using point locations of the farmstead. This has obvious accuracy issues (see [54] for a discussion on positional error in epidemiological studies), as farms may expand out across a landscape and is often associated with a number of farm parcels. However, research has shown that in large scale epidemiological investigations, the farm location can perform well as a practical indicator of farm location [55]. Durr \& Fraggatt [55] investigated a number of point geo-referencing systems (centroids, post-codes, farm building location) for farms in Cornwall, England to find the single "best" point location. Overall, centroids performed best in terms of identifying with the largest area of the farm; however the authors judged the farmstead location was the overall best practical point location. The authors highlight the benefits of using the farmstead as it can often be close to the focal point for housed animals over winter, and a centre of activities such as calf rearing and milking. Despite this, Durr \& Fraggatt [55] highlight how using the farmstead underperforms where there is extensive numbers of land parcels associated with a farm, which is often the case in Northern Ireland.

The long-term weather datasets may reflect climate variation across Northern Ireland, rather than shorter term weather variation that may drive fluke prevalence. When using post-mortem meat inspection data, we are uncertain when during the life of the animal were they infected with fluke. The mean age of animals was 3.2 years $\left(95^{\text {th }}\right.$ percentile: 12.6 years old), with the oldest animals being born in 1997. Therefore, we used the aggregated climate data, but future studies may benefit from reducing the cohort to younger animals and associating the outcome with weather variables over shorter temporal periods. Previous studies have used both longterm and recent weather variables to predict fluke risk, with both longer- and shorter-term datasets being useful depending on the attributes of the data and the period over which they were collected $[19,26]$.

\section{Conclusion}

The study has shown that fluke infection levels are high in Northern Ireland at animal- and herd- levels, as assessed by post-mortem meat inspection data. The 
majority of herds in Northern Ireland had some animals infected with liver fluke; however, there was significant variation in within-herd prevalence. There was significant spatial variation in risk of herd having high withinherd prevalence, which was associated with variations in long-term weather variables, herd enterprise type and the abattoir processing the animals. We have demonstrated that despite the limitations of using meat inspection data (for example, low test sensitivity and not being able to assign period of exposure to positive animals), they provide a significant cost-effective epidemiological resource that may have been underutilised. The analyses presented will provide useful information for further testing of epidemiological hypotheses in Northern Ireland (e.g. the effects of concurrent infection on disease disclosure).

\section{Additional file}

Additional file 1: Summary of predictor variables (Table S1-S5), example of spatial distribution of residuals and semi-variogram (Figures S1-S2), distribution and prediction maps (Figures S3-S10), and calibration graphs for GLM models (Figure S11-S13). (DOCX 6797 kb)

\section{Competing interests}

The authors declare that they have no competing interests.

\section{Authors' contributions}

AWB conceived and designed the study, extracted and statistically analysed data. SMcB extracted and manipulated raw data. RS, SMcD, JMcN, AWB contributed to the development of the grant proposal for the study. AWB wrote the manuscript, with contributions from RS, JMCN, ALM, MG and SMCD. All authors read and approved the final manuscript.

\section{Acknowledgements}

The authors wish to thank G. Byrne (Veterinary Service, DARD), M. Van Eyk (Veterinary Service, DARD) and S. Coogan (Meat Inspection, DARD) for advice on surveillance and processing of animal carcasses for liver fluke. We also wish to acknowledge Drs. P. Skuce and R. Zadoks for discussions and comments on an early draft of this work.

\section{Funding}

This work was financially supported by the Department of Agriculture and Rural Development (DARD), Northern Ireland under the Evidence and Innovation Strategy, and was one component of the project 15-3-10ffp-PMB3 (48005) "The role of endemic diseases and other factors in the occurrence of bovine Tuberculosis". The funders played no role in the design, analysis, and interpretation of data, or the decision to publish.

Received: 21 December 2015 Accepted: 3 April 2016 Published online: 14 April 2016

\section{References}

1. Schweizer G, Braun U, Deplazes P, Torgerson PR. Estimating the financial losses due to bovine fasciolosis in Switzerland. Vet Rec. 2005;157:188-93.

2. AFBI/DAFM. All Island Animal Disease Surveillence Report. A joint AFBI / DAFM Veterinary Laboratories publication. Agri-food and Biosciences Institute (AFBI), Belfast \& Department of Agriculture, Food and the Marine (DAFM), Dublin. 2014.

3. Fox NJ, White PC, McClean CJ, Marion G, Evans A, Hutchings MR. Predicting impacts of climate change on Fasciola hepatica risk. PLoS One. 2011;6:e16126.

4. Caminade C, van Dijk J, Baylis M, Williams D. Modelling recent and future climatic suitability for fasciolosis in Europe. Geospat Health. 2015;9:301-8.
5. Fairweather I. Reducing the future threat from (liver) fluke: realistic prospect or quixotic fantasy? Vet Parasit. 2011;180:133-43.

6. Charlier J, Vercruysse J, Morgan E, Van Dijk J, Williams DJ. Recent advances in the diagnosis, impact on production and prediction of Fasciola hepatica in cattle. Parasitology. 2014;141:326-35.

7. Mcllroy SG, Goodall EA, Stewart DA, Taylor SM, McCracken RM. A computerised system for the accurate forecasting of the annual prevalence of fasciolosis. Prev Vet Med. 1990;9:27-35.

8. Goodall EA, Menzies FD. Mathemetical modelling for the control and prevention of animal production diseases. IMA J Manag Math. 1993;5:337-47.

9. Ekstam B, Johansson B, Dinnétz P, Ellström P. Predicting risk habitats for the transmission of the small liver fluke, Dicrocoelium dendriticum to grazing ruminants. Geospat Health. 2011;6:125-31.

10. Durr PA, Tait N, Lawson AB. Bayesian hierarchical modelling to enhance the epidemiological value of abattoir surveys for bovine fasciolosis. Prev Vet Med. 2005;71:157-72.

11. Yilma JM, Malone JB. A geographic information system forecast model for strategic control of fasciolosis in Ethiopia. Vet Parasit. 1998;78:103-27.

12. Murphy TM, Fahy KN, McAuliffe A, Forbes AB, Clegg TA, O'Brien DJ. A study of helminth parasites in culled cows from Ireland. Prev Vet Med. 2006;76:1.

13. Dupuy C, Morignat E, Maugey X, Vinard JL, Hendrikx P, Ducrot C, Calavas D, Gay E. Defining syndromes using cattle meat inspection data for syndromic surveillance purposes: a statistical approach with the 2005-2010 data from ten French slaughterhouses. BMC Vet Res. 2013;9:88.

14. Halasa T, Frankena K, Olsen A, Bodker R, Toft N. Prevalence, risk factors and spatial analysis of infections with liver flukes in Danish cattle herds. Proceedings of the Society for Veterinary Epidemiology and Preventive Medicine 2015 (pp. 230-238).

15. Olsen A, Frankena K, Rene'Bødker NT, Thamsborg SM, Enemark HL, Halasa T. Prevalence, risk factors and spatial analysis of liver fluke infections in Danish cattle herds. Parasit Vectors. 2015;6:7.

16. Toolan DP, Mitchell G, Searle K, Sheehan M, Skuce PJ, Zadoks RN. Bovine and ovine rumen fluke in Ireland-prevalence, risk factors and species identity based on passive veterinary surveillance and abattoir findings. Vet Parasitol. 2015;212:168-74.

17. Ross JG. The Stormont "wet day" forecasting system for fascioliasis. Brit Vet J. 1970;126:401-8

18. Selemetas $N$, de Waal T. Detection of major climatic and environmental predictors of liver fluke exposure risk in Ireland using spatial cluster analysis. Vet Parasitol. 2015;209:242-53.

19. Selemetas N, Phelan P, O'Kiely P, de Waal T. Cluster analysis of fasciolosis in dairy cow herds in Munster province of Ireland and detection of major climatic and environmental predictors of the exposure risk. Geospat Health. 2015:9:271-9.

20. Selemetas N, Phelan P, O'Kiely P, de Waal T. The effects of farm management practices on liver fluke prevalence and the current internal parasite control measures employed on Irish dairy farms. Vet Parasitol. 2015; 207:228-40

21. Cooper KM, McMahon C, Fairweather I, Elliott CT. Potential impacts of climate change on veterinary medicinal residues in livestock produce: An island of Ireland perspective. Trends Food Sci Tech. 2014;1:21-35.

22. Flynn RJ, Mulcahy G, Welsh M, Cassidy JP, Corbett D, Milligan C, Andersen P, Strain S, McNair J. Co-infection of cattle with Fasciola hepatica and Mycobacterium bovis-immunological consequences. Transbound Emerg Dis. 2009:56:269-74.

23. Claridge J, Diggle P, McCann CM, Mulcahy G, Flynn R, McNair J, Strain S, Welsh M, Baylis M, Williams DJ. Fasciola hepatica is associated with the failure to detect bovine tuberculosis in dairy cattle. Nat Commun. 2012;3:853.

24. Lahuerta-Marin A, Gallagher M, McBride S, Skuce R, Menzies F, McNair J, McDowell SW, Byrne AW. Should they stay, or should they go? Relative future risk of bovine tuberculosis for interferon-gamma test-positive cattle left on farms. Vet Res. 2015;46:1-7.

25. Wagner B, Salman MD. Strategies for two-stage sampling designs for estimating herd-level prevalence. Prev Vet Med. 2004;66:1-7.

26. McCann CM, Baylis M, Williams DJ. The development of linear regression models using environmental variables to explain the spatial distribution of Fasciola hepatica infection in dairy herds in England and Wales. Int J Parasitol. 2010:40:1021-8.

27. Fuller RM, Smith GM, Sanderson JM, Hill RA, Thomson AG. The UK Land Cover Map 2000: construction of a parcel-based vector map from satellite images. Cartographic J. 2002:39:15-25. 
28. Ribeiro Jr PJ, Diggle PJ. geoR: A package for geostatistical analysis. R News 2001;1:14-8.

29. R Core Team. R: A language and environment for statistical computing. $R$ Foundation for Statistical Computing, Vienna, Austria. 2015. URL http:// www.R-project.org/

30. Papke LE, Wooldridge J. Econometric methods for fractional response variables with an application to 401 (k) plan participation rates. J Appl Econ. 1996;11:619-32.

31. Moser BK, Coombs LP. Odds ratios for a continuous outcome variable without dichotomizing. Stat Med. 2004;23:1843-60.

32. Steyerberg EW, Vickers AJ, Cook NR, Gerds T, Gonen M, Obuchowski N, Pencina MJ, Kattan MW. Assessing the performance of prediction models: a framework for some traditional and novel measures. Epidemiology. 2010;21:128.

33. Byrne AW, Acevedo P, Green S, O'Keeffe J. Estimating badger social-group abundance in the Republic of Ireland using cross-validated species distribution modelling. Ecol Indic. 2014;43:94-102.

34. Dohoo IR, Martin SW, Stryhn H. Veterinary Epidemiological Research VER Inc. Prince Edward Island, Canada: Charlottetown; 2009.

35. Arias $M$, Lomba C, Dacal V, Vázquez L, Pedreira J, Francisco I, Piñeiro P, Cazapal-Monteiro C, Suárez JL, Díez-Baños P, Morrondo P. Prevalence of mixed trematode infections in an abattoir receiving cattle from northern Portugal and north-west Spain. Vet Rec. 2011;168:408.

36. Ross JG. An abattoir survey of cattle liver infections with Fasciola hepatica. Brit Vet J. 1966;122:489-94.

37. Rapsch C, Schweizer G, Grimm F, Kohler L, Bauer C, Deplazes P, Braun U, Torgerson PR. Estimating the true prevalence of Fasciola hepatica in cattle slaughtered in Switzerland in the absence of an absolute diagnostic test. Int J Parasitol. 2006;36:1153-8.

38. Eckert J, Sauerlander R, Wolff K. Háufigkeit und geographische Verbreitung von Fasciola hepatica in der Schweiz. Schweiz Arch Tierheilkd. 1975;117: 173-84.

39. Ducommun D, Pfister K. Prevalence and distribution of Dicrocoelium dendriticum and Fasciola hepatica infections in cattle in Switzerland. Parasitol Res. 1991;77:364-6.

40. Schweizer G, Plebani GF, Braun U. Prävalenz von Fasciola hepatica und Dicrocoelium dendriticum beim Rind: Untersuchung in einem Ostschweizer Schlachthof. Schweiz Arch Tierheilkd. 2003;145:177-9.

41. Novobilský A, Novák J, Björkman C, Höglund J. Impact of meteorological and environmental factors on the spatial distribution of Fasciola hepatica in beef cattle herds in Sweden. BMC Vet Res. 2015;11:128.

42. Novobilský A, Sollenberg S, Höglund J. Distribution of Fasciola hepatica in Swedish dairy cattle and associations with pasture management factors. Geospat Health. 2015;9:293-300.

43. Ducheyne E, Charlier J, Vercruysse J, Rinaldi L, Biggeri A, Demeler J, Brandt C, de Waal T, Selemetas N, Höglund J, Kaba J. Modelling the spatial distribution of Fasciola hepatica in dairy cattle in Europe. Geospat Health. 2015:9:261-70

44. Rinaldi L, Biggeri A, Musella V, de Waal T, Hertzberg H, Mavrot F, Torgerson PR, Selemetas N, Coll T, Bosco A, Grisotto L. Sheep and Fasciola hepatica in Europe: the GLOWORM experience. Geospat Health. 2015;9:309-17.

45. Mons G. Leverbot rukt op. Melkveemagazine. 2012;1:12-3.

46. Bennema S, Vercruysse J, Claerebout E, Schnieder T, Strube C, Ducheyne E, Hendrickx G, Charlier J. The use of bulk-tank milk ELISAs to assess the spatial distribution of Fasciola hepatica, Ostertagia ostertagi and Dictyocaulus viviparus in dairy cattle in Flanders (Belgium). Vet Parasitol. 2009;165:51-7.

47. Conceição MA, Durão RM, Costa IM, Castro A, Louzã AC, Costa JC. Herdlevel seroprevalence of fasciolosis in cattle in north central Portugal. Vet Parasitol. 2004;123:93-103.

48. Kuerpick B, Conraths FJ, Staubach C, Froehlich A, Schnieder T, Strube C. Seroprevalence and GIS-supported risk factor analysis of Fasciola hepatica infections in dairy herds in Germany. Parasitology. 2013;140:1051-60.

49. Frankena K, White PW, O'Keeffe J, Costello E, Martin SW, Van Grevenhof I, More SJ. Quantification of the relative efficiency of factory surveillance in the disclosure of tuberculosis lesions in attested Irish cattle. Vet Rec. 2007; 161:679-84.

50. Olea-Popelka F, Freeman Z, White P, Costello E, O'Keeffe J, Frankena K, Martin W, More S. Relative effectiveness of Irish factories in the surveillance of slaughtered cattle for visible lesions of tuberculosis, 2005-2007. Irish Vet J. 2012;65:2.

51. Hadorn DC, Stärk KD. Evaluation and optimization of surveillance systems for rare and emerging infectious diseases. Vet Res. 2008;39:1.
52. Collins JD. Meat plant surveillance and its role in the eradication of tuberculosis in cattle. Selected Papers Dublin: Tuberculosis Investigation Unit. Dublin, Ireland: University College Dublin; 1996;55-59.

53. De Roeck E, Van Coillie F, De Wulf R, Soenen K, Charlier J, Vercruysse J, Hantson W, Ducheyne E, Hendrickx G. Fine-scale mapping of vector habitats using very high resolution satellite imagery: a liver fluke case-study. Geospat Health. 2014;8:671-83.

54. Jacquez GM. A research agenda: Does geocoding positional error matter in health GIS studies? Spat Spatiotemporal Epidemiol. 2012;3:7-16.

55. Durr PA, Froggatt AE. How best to geo-reference farms?: A case study from Cornwall, England. Prev Vet Med. 2002;56:51-62.

\section{Submit your next manuscript to BioMed Central and we will help you at every step:}

- We accept pre-submission inquiries

- Our selector tool helps you to find the most relevant journal

- We provide round the clock customer support

- Convenient online submission

- Thorough peer review

- Inclusion in PubMed and all major indexing services

- Maximum visibility for your research

Submit your manuscript at www.biomedcentral.com/submit
) Biomed Central 